\title{
A Review Paper on Textile Fiber Identification
}

\author{
${ }^{1}$ Prof. Dr.Engr Ayub Nabi Khan \\ ${ }^{2}$ Nafis Abir \\ ${ }^{2}$ Mohammad Abu Nasir Rakib \\ ${ }^{3}$ E.M Saberin Bhuiyan \\ $\&{ }^{4 *}$ Md.Ramij Howlader \\ ${ }^{I}$ Pro-VC, BUFT C.Text.FTI, Manchester.UK B.Sc in Text.Technology, DU M.Sc \& Ph.D in Text. Technology, \\ UMIST, Manchester, U.K. \\ ${ }^{2}$ Lecturer, Dept. of Textile Engineering, BUFT ,B.Sc in Textile Engineering (AUST) \\ ${ }^{2}$ Lecturer, Dept. of Textile Engineering \& Management, BUFT ,B.Sc in Textile Engineering (CU) \\ ${ }^{3}$ B.Sc in Textile Engineering (BUFT) \\ 4*Lecturer (TE), BUFT ,B.Sc in Textile Engineering (DUET), M.Sc in Textile Engineering (BUTex)
}

\begin{abstract}
Fiber identification is the most important things to design a specific purpose dress. In this study, different textile fibers are identified through both technical and non-technical test. Technical test can be microscopic and chemical test \& non-technical test can be feeling and burning test. Technical test is more authentic than non-technical test due to its accuracy.
\end{abstract}

Keywords: Fiber Identification, Technical and Non-Technical Test, Microscopic and Chemical Test, Feeling and Burning Test etc.

\section{Introduction}

The strategy of identification varied with the purpose (choice of treatment, assessment of damage or identification of its cause, or authentication) but most of all with the condition of the fibers. Fibers from ethnographic or archaeological sources tend to be aged, and are sometimes fragmentary or decayed, fossilized or charred. With fibers in such condition, the simpler methods of preparation for microscopic observation were found more successful than the classical biological methods of soaking, clearing and staining. Not all fibers could be identified. Fur fibers from characteristic areas of the pelt were usually diagnostic as to species as well as to genus [1]. Vegetable fibers were often not morphologically specific to species. Unless "guide elements" were present, or special limitations on species distribution were known, the identification of the genus of a vegetable fiber was often the best that could be done. Instructions for an optical test for flax, and a report form for the observation of fur and wool fibers, are included. The identification of fibers in archaeological and ethnographic objects in practice is a great deal more difficult than the texts on fiber identification lead one to believe [2].

For example, the solubility tests which are a mainstay of synthetic fiber identification are of no use since archaeological and ethnographic fibers are natural ones. The various chloroiodine stains, Herzberg's and others which stain cellulose red, violet or blue and ligno-cellulose yellow, seldom act on old and desiccated fiber unless at nodes or points of fracture [3]. These and many other methods recommended for use with textile fiber identification often give equivocal results when applied to archaeological or ethnographic material. Experience has shown that complicated and lengthy preparation procedures do not repay the time and effort they require and, more importantly, often fail altogether. Perhaps the single most useful generalization that can be made about archaeological and ethnographic fiber identification is that not all fibers can be identified on the basis of the information we now have. Nevertheless, a surprising number of these fibers can be identified, or at least classified, by microscopically observation and a few simple tests [4].

\subsection{Fiber Sample:}

\section{Materials and methods}

Different types of fiber sample collected from local market to perform various test to identify actual origin and conventional name. Examples: cotton, wool, silk, linen, nylon polyester etc.

\subsection{Testing Methods:}

2.2.1. The Non Technical Test:

a) Feeling Test: The feeling test requires perception if it is to be of any value. Skilled perception is acquired only after handling many different fabrics over a period of time. Limitations of this test become apparent when 
examining and comparing fabrics of different fiber content. Feeling test involves touching a fabric and feeling the fabric to know its component fibers. For example, wool fabrics will feel warm when touched because the heat generated by wool, which is a nonconductor of heat, will remain in the touched area itself. On the other hand, the fabrics made up of plant fibers such as cotton fabrics, linen fabrics and even the rayon, that are made from the cellulose of wood pulp or cotton fiber, feel cool to touch. As they are conductors of heat, the heat generated by the finger passes off making the fabric cold. However, it requires a long experience of handling different fabrics over a period of time for such skillful perception. Also, it is difficult to examine and compare the fabrics made of different fiber contents with the feeling test. The other nontechnical test for fiber identification by the burn test- involves burning a sample of fabric and observing the various characteristics shown by it after burning in order to determine its fiber content. The burning test is more efficient than the feeling test but it also has its limitations. For example, fabrics made of bi-constituent fibers, that are combination of two different textile polymers, cannot be identified with this test [5].

b) Burning test: To identify the fibers in an unknown piece of fabric, a snippet should be cut off from it. This specimen should be about 1" long and a triangle at most 1/4" wide. The snippet of fabric should be held in a pair of tweezers over the dish (which has already been made fireproof). With either a match or cigarette lighter, the snippet should be put directly into the flame long enough for it to catch on fire. Most of the fabrics burn and they have to be extinguished. There are other fabrics that burn until there is nothing to burn, or they burn and go out on their own after a few seconds leaving remaining unburned fiber and are therefore self-extinguishing. There are certain other fabrics that do not burn even with a flame held directly to it. Fibers can also be identified through the smell of the smoke it gives off in burning and the ash or melted bead that remains after it has burned. Some of the fabrics are blends, and the blend of fibers may make the burn test rather unreliable test for fiber content. Moreover, some fabrics have chemical finishes and sizing applied to them that will change the way they burn, making the burn test further unreliable [5].

\subsubsection{The Technical Test:}

a) Microscopic Test: Microscopic test is a technical test that involves identifying the fabric with the help of a microscope with a magnification of minimum 100 powers. The test can easily distinguish between fibers. The test identifies the natural fibers more easily as compared to manmade ones. Synthetic fibers are very similar in appearance and the increase in the number of varieties makes it a little tough to distinguish the fibers even under a microscope [6-7].

b) Chemical Tests: Chemical tests are another technical means of identifying fibers. But chemical tests are not intended for the general consumers. Different types of chemical tests are undertaken to establish the identity of the fibers used. These tests give accurate and precise analysis and conducted in research laboratory.

* Stain Test: Also known as the Double Barrel Fiber Identification (DBFI), the test is based on the theory that each fiber has its own distinct two- color reaction when treated with stain. A fiber will turn to a particular color in the presence of dilute acetic acid and to some other specific color when stained in the presence of a mild alkali [5].

* Solvent Test: The test involves treating the fibers in certain solvents for identifying them. The technical test is becoming difficult to conduct as most of the manufactured fibers and their blends are chemically similar. There is no individual chemical or solvent test for separating or identifying the fibers in combinations [5].

\section{Result \& discussion}

3.1. Burning Behavior of Different Fibers:

\begin{tabular}{|c|c|c|c|c|c|}
\hline Fiber & Approaching & Stationary & Withdrawing & Odor & Residue \\
\hline Cotton & Ignites at first & Burns rapidly & $\begin{array}{c}\text { Smolders glows } \\
\text { smokes }\end{array}$ & $\begin{array}{c}\text { Burning papers } \\
\text { or leaves }\end{array}$ & $\begin{array}{l}\text { Soft gray not } \\
\text { much }\end{array}$ \\
\hline Linen & Ignite quickly & Burns rapidly & Burns actively & Burning paper & Soft gray, fine \\
\hline Wool & $\begin{array}{l}\text { Draws away } \\
\text { from flame }\end{array}$ & Melts, Burns & $\begin{array}{c}\text { Self- } \\
\text { extinguishing }\end{array}$ & $\begin{array}{c}\text { Burned feathers } \\
\text { or hair }\end{array}$ & $\begin{array}{c}\text { Crushable } \\
\text { brittle black }\end{array}$ \\
\hline Silk & $\begin{array}{l}\text { Draws away } \\
\text { from flame }\end{array}$ & Melts, Burns & $\begin{array}{c}\text { Self- } \\
\text { extinguishing }\end{array}$ & $\begin{array}{c}\text { Burned feathers } \\
\text { or hair }\end{array}$ & $\begin{array}{c}\text { Crushable } \\
\text { brittle black }\end{array}$ \\
\hline Rayon & $\begin{array}{l}\text { Ignites in } \\
\text { contact }\end{array}$ & Burns & Burns slowly & Burning paper & Little or no ash \\
\hline Acetate & $\begin{array}{l}\text { Melts before } \\
\text { contact }\end{array}$ & $\begin{array}{l}\text { Melts burns } \\
\text { with yellow } \\
\text { flame }\end{array}$ & Melts & $\begin{array}{c}\text { Burning paper } \\
\text { and vinegar }\end{array}$ & Hard dark bead \\
\hline
\end{tabular}


A Review Paper on Textile Fiber Identification

\begin{tabular}{|c|l|l|c|c|c|}
\hline Nylon & $\begin{array}{l}\text { Draws away and } \\
\text { melts }\end{array}$ & $\begin{array}{l}\text { Melts, burn and } \\
\text { drips }\end{array}$ & $\begin{array}{l}\text { Burns with } \\
\text { difficulty }\end{array}$ & Celery & $\begin{array}{c}\text { Hard bead } \\
\text { cream color or } \\
\text { dark }\end{array}$ \\
\hline Polyester & $\begin{array}{l}\text { Melts before } \\
\text { contact }\end{array}$ & $\begin{array}{l}\text { Melts burns } \\
\text { black smoke }\end{array}$ & $\begin{array}{l}\text { Burns for a } \\
\text { while ; self- } \\
\text { extinguishing }\end{array}$ & $\begin{array}{c}\text { Sweet } \\
\text { chemicals }\end{array}$ & $\begin{array}{c}\text { Hard bead } \\
\text { cream color or } \\
\text { dark }\end{array}$ \\
\hline Acrylic & $\begin{array}{l}\text { Melts burns } \\
\text { before reaching } \\
\text { flames }\end{array}$ & Melts burn & Sputters, burns & Boiled fish & $\begin{array}{c}\text { Hard irregular } \\
\text { bead, }\end{array}$ \\
\hline
\end{tabular}

Table1. Burning characteristics of textile fibers [5].

\subsection{X-sectional and Longitudinal View of Different Fibers:}

When it comes for fiber identification, it is very difficult to identify a fiber with bare eyes. A microscopic view of the fiber helps to classify and identify it easily. There are some other tests like burning test and chemical test for fiber identification. In the following images Longitudinal and cross-section views have been shown for common natural and man-made fibers. Name of fibers are labeled under the image [8-16].
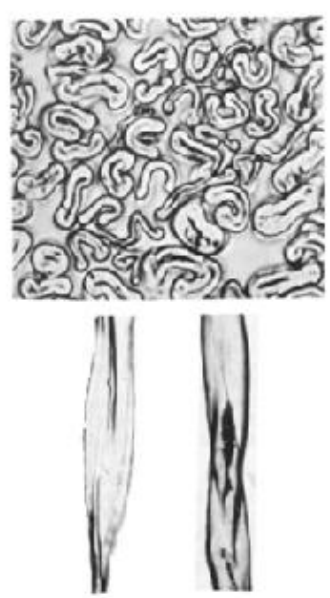

Fig. 1 Cotton, not mercerized

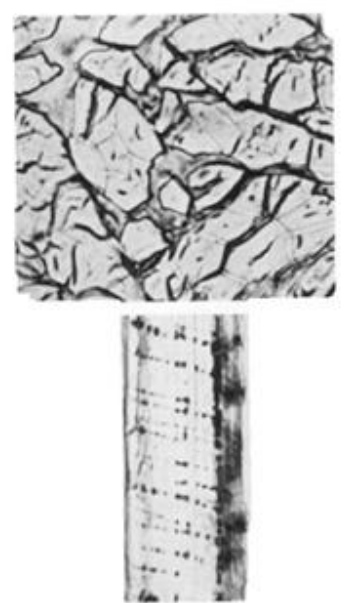

Fig. 4 Hemp
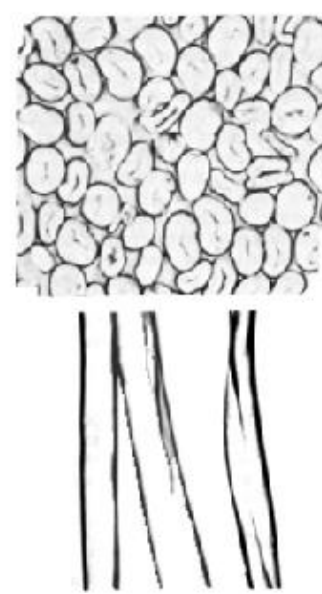

Fig. 2 Cotton, Mercerized
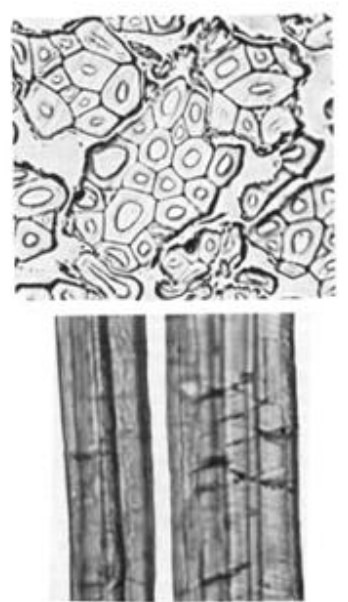

Fig. 5 Jute
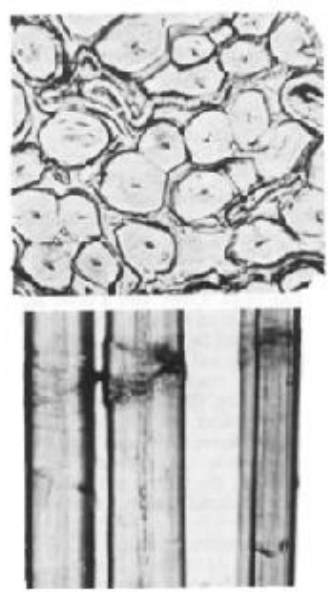

Fig. 3 Flax
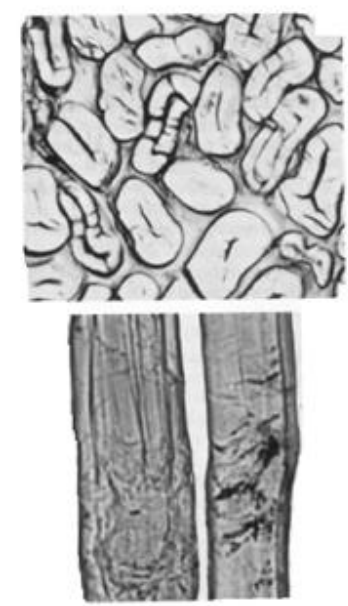

Fig. 6Ramie 

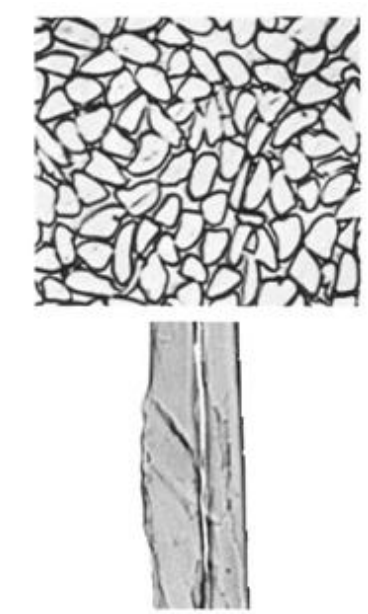

Fig. 7 Silk
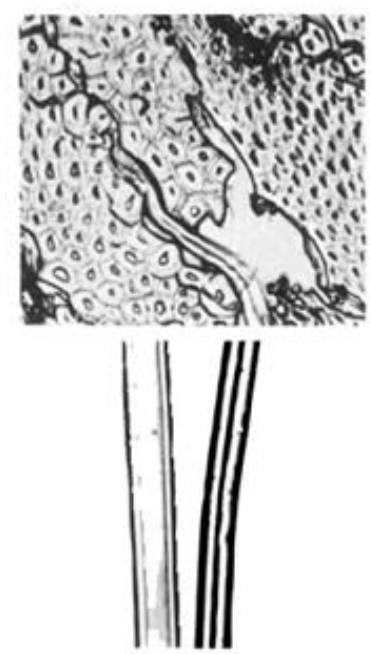

Fig. 10 Phormium
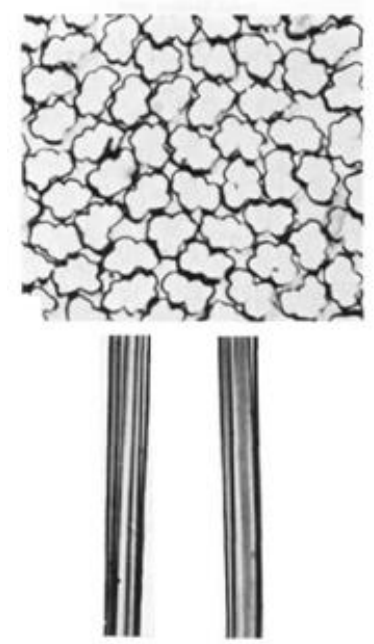

Fig. 13 Acetate, Secondary
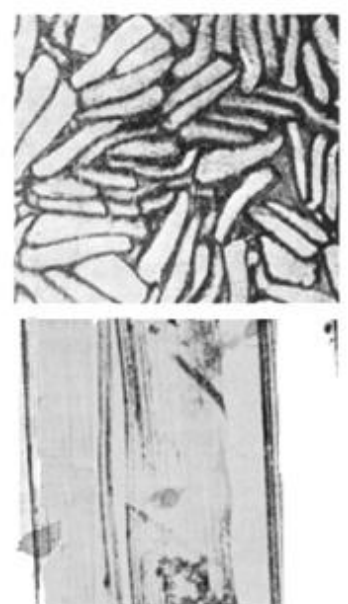

Fig. 8 Silk, Tussah
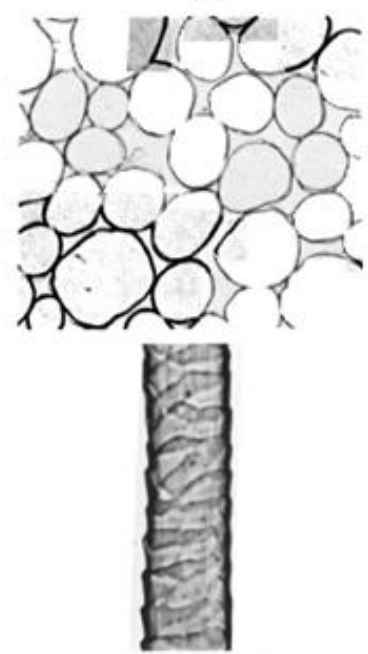

Fig. 11 Woo
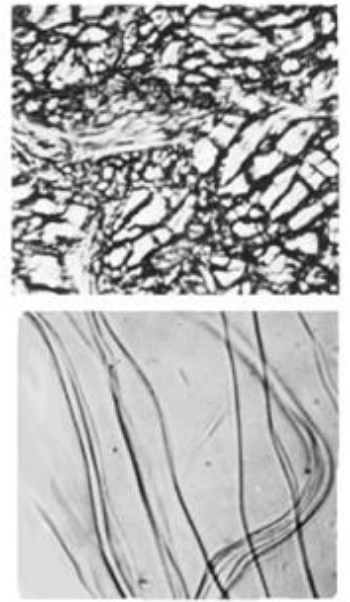

Fig. 9 Asbestos
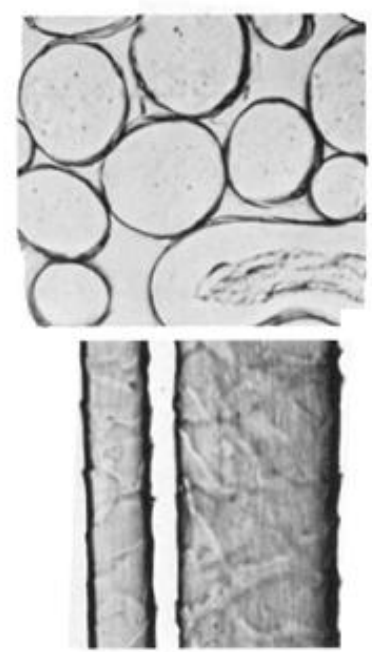

Fig 12. Mohair
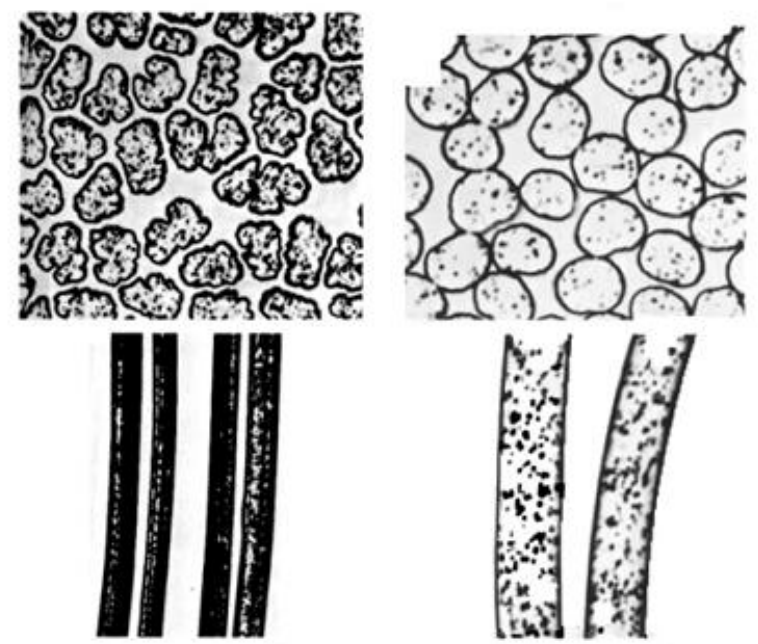

Fig. 14 Triacetate 25 Den, dull luster Fig. 15 Acrylic, Reg. wet spun, Semi dull 

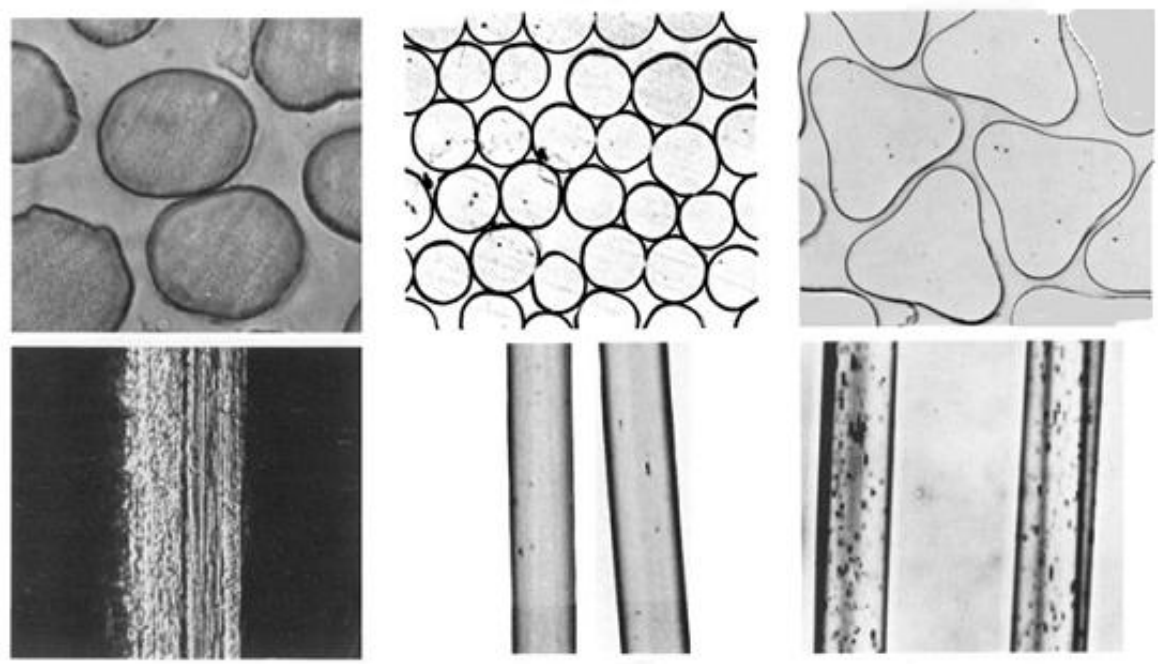

Fig. 16 Modacrylic

Fig. 17 Nylon, bright

Fig. 18 Nylon, Low modification ratio trilobal

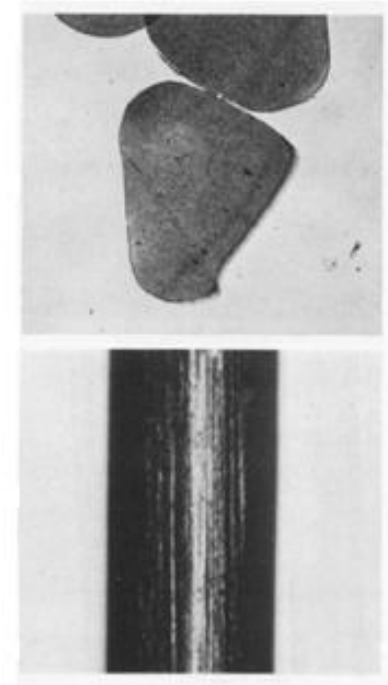

Fig. 19 Polyethylene, medium density
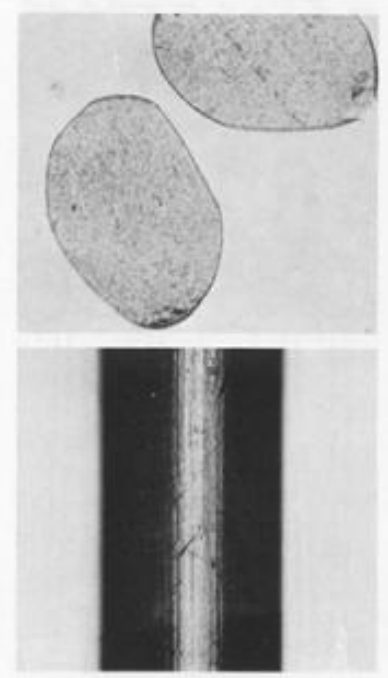

Fig. 20 Polyethylene, high density

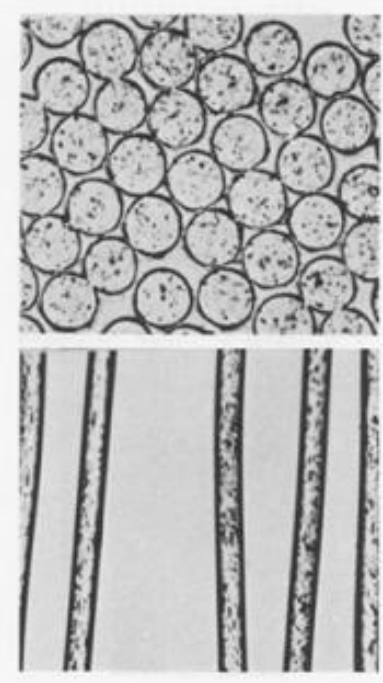

Fig. 21 Polyester, Regular melt spun, 30 denierper filament, semi dul 


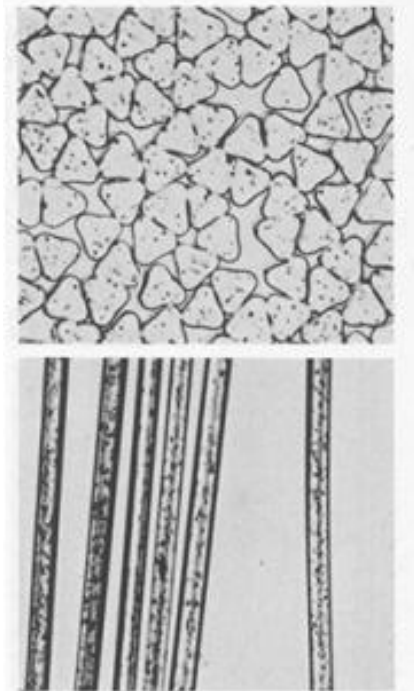

Fig. 22 Polyester, low modification ratio trilobal, 1.4 denier per filament, semidull luster

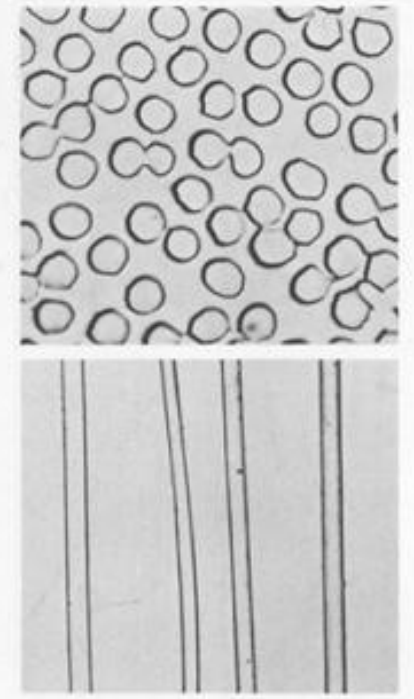

Fig 23 Rayon, cuprammonium 1.3 denier per filament bright luster

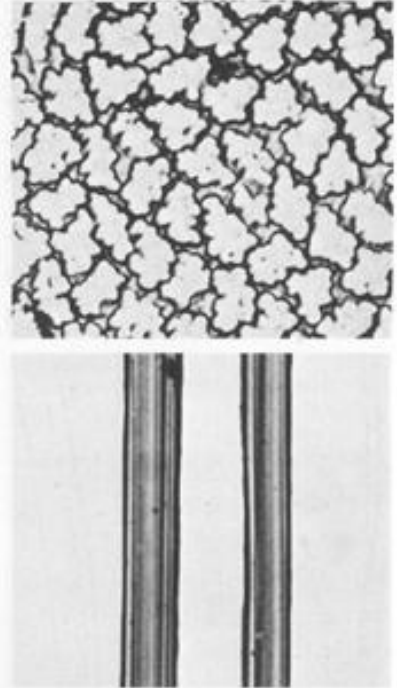

Fig. 24 Rajon, viscose, Regular tenacity

\subsection{Actions against Chemicals:}

1. Distinguishing animal from vegetable fibers with an acid: As strong alkali destroy animal substances; a $5 \%$ of soda lye solution in water can be used to eliminate wool and silk fibers from a sample that contains a mixture of fiber. The vegetable fibers will not be affected by this solution [5].

2. Distinguishing vegetable from animal fibers with an acid: As dilute acid destroy vegetable fibers, a $2 \%$ sulphuric acid solution can be used. A drop of solution is placed on the sample, which is then pressed with a hot iron. The spotted area will become charred if the sample is cotton linen or rayon [5].

3. Distinguishing Silk from Wool: The use of concentrated cold hydrochloric acid will dissolve the silk and the wool fiber swells [5 \& 17].

4. Distinguishing Nylon From Other Fibers: If the fabric is thought to contain nylon, the fabric may be immersed in a boiling solution of sodium hydroxide. The nylon is insoluble in such a solution [5].

5. Distinguishing Polyesters From other Fibers: Polyester is soluble in hot Meta cresol, however, unlike acetate it is not soluble in acetone, and unlike nylon it is not soluble in concentrated formic acid [5 \& 18].

6. Distinguishing Acrylics From other Fibers: Acrylic fibers will dissolve in 70 percent solution of ammonium thio-cyanate at 130 degree Celsius but the other fibers will not [5 \&18].

7. Distinguishing Linen From Cotton: Cotton and linen are immersed in a $1 \%$ solution of fuchsine in alcohol to give red rose color. Later, they are washed and immersed into ammonia, linen retains the red coloration but cotton does not [5].

8. Distinguishing Glass Fibers from Other fibers: There are two specific solvents for quick identification of glass fibers, they are hydrofluoric acid and hot phosphoric acid [5].

\section{Conclusion}

Identification of textile fiber is very important factors for research and development. By identifying different fibers by different test we know the physical and chemical composition of various fibers. It is also very important factors for using a cloth because if we used polyester shirt in high temperature then it will be melts. Since we know that polyesters are melt in high temperature so we never used polyester in shirt in high temperature.

\section{References}

[1] Goodway, M. (1987). Fiber identification in practice. Journal of the American Institute for Conservation, 26(1), 27-44.

[2] Luniak, B. (1953). The identification of textile fibres: qualitative and quantitative analysis of fibre blends.

[3] Perry, D. R., Appleyard, H. M., Cartridge, G., Cobb, P. G. W., Coop, G. E., Lomas, B., ... \& Farnfield, C. A. (1985). Identification of textile materials. Textile Institute.

[4] Houck, M. M. (Ed.). (2009). Identification of textile fibers. Elsevier.

[5] Corbman, B. P. (1983). Textiles. Fiber to fabric. Gregg/McGraw-Hill Marketing Series; McGraw-Hill. Gregg Division

[6] Martin Brown, F. "The microscopy of mammalian hair for microscopists," Proceedings of the American Philosophical Society 85 (1942) 250-274.

[7] Stoves, J. L., Fibre Microscopy, Princeton 1958. 
[8] Zafeiropoulos, N. E., Williams, D. R., Baillie, C. A., \& Matthews, F. L. (2002). Engineering and characterisation of the interface in flax fibre/polypropylene composite materials. Part I. Development and investigation of surface treatments. Composites part A: applied science and manufacturing, 33(8), 1083-1093

[9] Lansing, A. I., Rosenthal, T. B., Alex, M., \& Dempsey, E. W. (1952). The structure and chemical characterization of elastic fibers as reveled by elastase and by electron microscopy. The Anatomical Record, 114(4), 555-575

[10] Reddy, N., \& Yang, Y. (2005). Structure and properties of high quality natural cellulose fibers from cornstalks. Polymer, 46(15), 5494-5500.

[11] Oh, S. Y., Yoo, D. I., Shin, Y., Kim, H. C., Kim, H. Y., Chung, Y. S., ... \& Youk, J. H. (2005). Crystalline structure analysis of cellulose treated with sodium hydroxide and carbon dioxide by means of X-ray diffraction and FTIR spectroscopy. Carbohydrate Research, 340(15), 2376-2391

[12] Yueping, W., Ge, W., Haitao, C., Genlin, T., Zheng, L., QunFeng, X., ... \& Xushan, G. (2009). Structures of natural bamboo fiber for textiles. Textile research journal.

[13] Um, I. C., Kweon, H., Park, Y. H., \& Hudson, S. (2001). Structural characteristics and properties of the regenerated silk fibroin prepared from formic acid. International journal of biological macromolecules, 29(2), 91-97

[14] Fink, H. P., Weigel, P., Purz, H. J., \& Ganster, J. (2001). Structure formation of regenerated cellulose materials from NMMOsolutions. Progress in Polymer Science, 26(9), 1473-1524.

[15] Hearle, J. W., \& Morton, W. E. (2008). Physical properties of textile fibres. Elsevier.

[16] Ma, H., Zeng, J., Realff, M. L., Kumar, S., \& Schiraldi, D. A. (2003). Processing, structure, and properties of fibers from polyester/carbon nanofiber composites. Composites Science and Technology, 63(11), 1617-1628.

[17] Appleyard, H. M., Guide to the Identification of Animal Fibres, second edition, Leeds 1978.

[18] Culliford, B. J. (1963). The multiple entry card index for the identification of synthetic fibres. Journal of the Forensic Science Society, 4(2), 91-97. 